\title{
Role for academic institutions and think tanks in speeding progress on sustainable development goals
} (ब) (1) $\Theta$ OPEN ACCESS

Academic institutions and think tanks are uniquely placed to broker links between different sectors and assist with cross cutting approaches to achieving the health related sustainable development goals, say Ilona Kickbusch and Johanna Hanefeld

\author{
Ilona Kickbusch director ${ }^{1}$, Johanna Hanefeld associate professor health policy and systems ${ }^{2}$ \\ ${ }^{1}$ Global Health Centre Graduate Institute, Geneva, Switzerland; '2London School of Hygiene and Tropical Medicine, London, UK
}

\begin{abstract}
In September 2015, countries at the United Nations General Assembly adopted the 17 sustainable development goals (SDGs), a set of targets for 2030 to mobilise action on three interwoven dimensions of our existence-people, planet, and prosperity. The problems facing humanity and the planet are now acknowledged as being too large to be tackled by specific sectors-such as health, education, or trade-alone. In recognition of this, the SDGs expanded the scope of their predecessors, the millennium development goals (MDGs), and moved away from a siloed approach. While three of the eight MDGs concentrated on health, only one of the SDGs (goal 3) is focused on the broad goal of health and wellbeing for all. However, health is explicitly mentioned in many others and is connected with all 17 goals and 169 targets. This means that meeting the goals for health, as well as the other SDG targets, will require the involvement of a diverse set of actors.
\end{abstract}

\section{Transformative governance for health}

The World Health Organization has described the SDGs as providing "a new and exciting opportunity to strengthen governance for health." 2 That is, making health a focus of decision making outside of what has traditionally been considered the health sector, and fostering joint action between sectors. Achieving any of the targets in goal 3-which include universal health coverage, the reduction of premature mortality from non-communicable diseases, and improving maternal and child health—will require an approach that involves other sectors, as well as transformative policies and political commitment.

WHO has reinforced its call for cross cutting approaches to the achievement of the health targets and sees the main game of the SDGs for health played out beyond the constraints of the health sector, involving a variety of non-health actors, including non-state actors. ${ }^{2}$ This requires approaches which build alliances around "implementation packages" rather than individual matters or diseases. Such approaches need to focus on enabling co-production and co-benefits, and recognising that sustainable development for people and the planet cannot be achieved by one sector alone. Examples include goals that address climate action (goals 6,7,11, and 13) or that tackle food and nutrition (goals 2, 12, and 15). While they are not explicitly health focused, health is an essential part of these goals and, in turn, achieving them is essential to goal 3 of achieving health and wellbeing for all.

In order to move towards joint implementation, countries will benefit from the creation, sharing, and brokering of new knowledge on governance because there is still a major gap in the understanding that health is a precondition for, and an outcome and indicator of, all three political spaces of sustainable development (economic, social, and environmental). ${ }^{3}$

The importance of cross cutting governance in achieving the SDGs is implicit across most of the targets, and the final two goals address this need explicitly. Goal 16 is dedicated to promoting peace, stability, human rights, and effective governance through strong institutions, based on the rule of law. It is often considered the "governance SDG." It is clear that without strong institutions, for example in public health or for universal health coverage, the health SDG targets will not be achieved. Through its targets, goal 17 underpins the importance of partnerships between governments, the private sector, and civil society in achieving sustainable development. Applying an integrated approach to the SDGs is challenging at all levels of governance and requires whole of government and whole of society involvement. 
The global health community has a head start in applying an integrative approach to policy making because it can build on several decades of work in implementing Health in All Policies. Health in All Policies is an approach to public policy that means systematically taking into account the health implications of decisions across all sectors. It seeks synergies between sectoral actions and avoids harmful health impacts to improve population health and health equity. It improves the accountability of policy makers for health impacts at all levels of policy making. This includes an emphasis on the consequences of public policies on health systems and the determinants of health and wellbeing. ${ }^{4}$

\section{Think tanks and academic institutions}

The achievement of the SDGs is dependent on national governments taking ownership and establishing policies, plans, and programmes. The political reality of each country-which includes economic policies and systems, development agendas, social norms, social policies, political systems, and ideologies - will have a bearing on the achievement of the targets at a local level and therefore on the attainment of the SDG targets globally.

Think tanks and academic institutions are poised to play a key role in political decisions that aim to tackle inequalities, shape healthy living and working environments, and ensure universal health coverage at both a national and global level. ${ }^{5}$ This means not only analysing and assessing progress towards the goals, but also acting as knowledge brokers between sectors and stakeholders to enable greater dialogue between the general public, decision makers, and wider society. A review of health think tanks in low and middle income countries, conducted in 2012, found great impact on health related policies in six case study countries. ${ }^{6}$

While the term "think tanks and academic institutions" covers a spectrum of organisations, these are usually acknowledged to be concerned with the creation and communication of policy relevant knowledge, often facilitating public dialogue and contributing to greater transparency of the policy process. ${ }^{7}$ Their recent proliferation in health has also been noted. While think tanks overall are seen as contributing to accountability and pluralistic debate in society it is important to keep in mind potential conflicts of interest, especially where there has been industry funding. ${ }^{7}$ In the UK, for example, research on alcohol regulation revealed the extent to which the alcohol industry specifically used think tanks to influence policy debates. ${ }^{8}$ This underlines the importance of an independent funding base for think tanks to safeguard their impartiality.

The convening role of think tanks and academic institutions is important both nationally and supra-nationally. They can bring together global policy actors with national level implementers and those most affected by global policies. Globally, enabling the exchange of experiences in relation to different policy, technical, and institutional options is a critical role for think tanks and academic institutions.

If think tanks and academic institutions are to fulfil their role in accelerating progress towards achieving the SDGs' health targets, a specific focus on the following six areas will be needed.

\section{Better governance for the SDGs}

Global health policy think tanks can support the 2030 sustainable development agenda and the SDGs by actively championing new governance mechanisms at country level that prominently position health as contributing to wider issues of equity. These should tackle health in the context of environmental challenges (planetary health), sustainable production and consumption, economic impact, and the broader determinants of wellbeing. They need to acknowledge the changed relationships between states and other actors. Equally, it is important to recognise the need to reach consensus at both the national and international level in order to ensure SDG implementation.

The focus should be on the political processes and institutional support needed at country level. It will be critical to develop mechanisms to manage trade-offs, and the means to ensure that what is needed to achieve one goal does not conflict with what is needed to achieve another. Without effective mechanisms that manage and negotiate the inter-dependence between the 17 goals, little will change.

\section{Political accountability for implementation}

Work by think tanks and academic institutions must emphasise the political determinants of health, which have been analysed by the Lancet-University of Oslo Commission on Global Governance for Health. ${ }^{9}$ There is a need to develop and strengthen SDG indicators which relate to political accountability that cut across traditional policy areas. This can include accountability in relation to resilience, global health security, and the development of global public goods. ${ }^{9}$ It means examining power dynamics across policy areas that affect health and that require transformative governance. Here the knowledge creation role of think tanks and universities is particularly important. It includes not only researching power, but also increasing accountability through public and independent monitoring of policy commitment.

\section{Stakeholder engagement}

Think tanks and academic institutions are powerful convening platforms. They need to reach out to actors at all levels of governance, from all sectors and all stakeholders, to discuss and develop policies that strengthen the implementation of the SDGs as they relate to health. This includes the global level as well as decision makers and stakeholders at the national level so as to create a productive interface between the levels of governance. The process needs to include all levels and means reaching out to city governments ${ }^{7}$; to regional bodies to increase their commitment to SDG implementation; and to global public goods that support health at home. It sees a special responsibility to reach out to civil society.

\section{Systemic challenges}

As convenors, think tanks and academic institutions should prioritise issues that are systemic, intersectoral, globally interdependent, and beyond any single country's capacity to solve. The determinants of health-poverty, environmental change, migration - and challenges such as antimicrobial resistance and health security are examples. This requires engaging with domestic actors with high policy clout and representatives of civil society, as well as global stakeholders. It is in these areas of "two level games" that think tanks can be particularly beneficial. ${ }^{8}$ The SDGs link domestic policies to the global system in new ways.

\section{Knowledge sharing and joint learning}

Think tanks and academic institutions focused on SDGs should be committed to universality. Knowledge should be considered a global public good and think tanks and other knowledge institutions should share learning and solutions beyond old divides at national, regional, and global levels. While each 
country might face unique challenges in achieving the goals, "universality" implies recognition that the SDGs provide a framework for tackling problems that require global cooperation. Motivated by the SDG agenda, the World Bank dropped the term "developing countries" from the 2016 edition of its World Development Indicators and no longer distinguishes between "developed" and "developing" countries in the presentation of its data-think tanks and academic institutions should follow suit and move beyond these descriptors. ${ }^{10}$

\section{Policy research}

Think tanks and academic institutions should be centres of excellence in research, with a special focus on policy research. The SDGs place greater demands on the scientific community than the MDGs because tackling systemic challenges and determinants requires research that takes many factors into account-social, economic, and environmental. Too little is known about the policy processes, connections, and tradeoffs that allow for successful SDG implementation. Research must help to develop new metrics, improve integrated monitoring, and strengthen evaluation mechanisms. Researchers must also ensure there is dialogue with policy makers at all levels and make their results easily accessible to all.

\section{The Global Health Policy Network of Think Tanks and Academic Institutions}

In recognition of the new challenges that the SDGs present, the Global Health Policy Network of Think Tanks and Academic Institutions (GHPTT network) was initiated in 2015. It aims to open new avenues for learning around policy making and implementation relating to the SDGs, in order that stakeholders and policy makers can benefit from the analysis of experiences from around the world. Convened by the Global Health Centre at the Graduate Institute in Geneva with support from the International Development Research Centre in Canada, the network now aims to drive change by building on the existing work of individual institutions.

The think tanks and academic institutions in the GHPTT network cover a range of interdisciplinary expertise. This includes national think tanks which work to engage the public, tackle innovation relating to SDG implementation, and hold governments to account; think tanks that provide a global forum for debate, enable sharing of national experiences, and can influence the global agenda; and academic institutions that may be best equipped to generate new knowledge and evidence. Because of the strong context dependency much of the work of the networks will be done through established regional hubs and through in-depth, country specific workshops.

To create sustainable development and prosperity for people and the planet means that no level of governance can continue with business as usual. Countries as well as international organisations, actors across all levels, and public and private stakeholders will need new knowledge and new ways of working. Think tanks and academic institutions have a critical role to play in this endeavour and the GHPTT network will contribute through the six functions set out here. We invite think tanks with such a governance focus to join the GHPTT network, so we can work together to achieve the SDGs.

Competing interest statement: IK is the chair and convenor of the Global Health Policy Think Tank Network and received a grant from IDRC to build and enable this network. JH is representing LSHTM on the steering committee of the GHPTT

The authors wish to acknowledge the members of the Global Health Policy Think Tank Network for their contributions

Contributors and sources: IK wrote the first draft of this paper. JH commented and revised the draft.

Provenance and peer review: Commissioned; externally peer reviewed. This article is one of a series commissioned by The BMJ based on an idea by the International Development Research Centre, Canada. The $B M J$ retained full editorial control over the selection of authors, external peer review, editing, and publication.

1 Jha A, Kickbusch I, Taylor P, Abbasi K. SDGs Working Group. Accelerating achievement of the sustainable development goals. BMJ 2016;352:1409. doi:10.1136/bmj.i409pmid: 26825535.

2 World Health Organization. World health statistics 2016: monitoring health for the SDGs, sustainable development goals. 2016. http://apps.who.int/iris/bitstream/10665/206498/1/ 9789241565264 eng.pdf?ua $=1$.

3 United Nations General Assembly. Resolution 66/288, The future we want, A/RES/66/288. 2012. http://www.un.org/ga/search/view doc. asp?symbol=A/RES/66/288\&Lang=E.

4 Kickbusch I. Health in All Policies: the evolution of the concept of horizontal health governance. Implementing health in all policies: 2010 (2010):11-24. www.who.int/ sdhconference/resources/implementinghiapadel-sahealth-100622.pdf

5 World Health Organization. Adelaide Statement II: outcome statement from the 2017 international conference Health in All Policies: progressing the sustainable development goals. 2017. http://www.who.int/social_determinants/SDH-adelaide-statement-2017.pdf? ua $=1$.

6 Bennett S, Corluka A, Doherty J, et al. Influencing policy change: the experience of health think tanks in low and middle income countries. Health Policy Plan 2012;27:194-203. doi: 10.1093/heapol/czr035pmid:21558320.

7 Shaw SE, Russell J, Greenhalgh T, Korica M. Thinking about think tanks in health care: a call for a new research agenda. Sociol Health IIIn 2014;36:447-61. doi:10.1111/14679566.12071pmid:24111597.

8 Hawkins B, McCambridge J. Industry actors, think tanks, and alcohol policy in the United Kingdom. Am J Public Health 2014;104:1363-9. doi:10.2105/AJPH.2013.301858pmid: 24922137.

9 Ottersen OP, Dasgupta J, Blouin C, et al. The political origins of health inequity: prospects for change. Lancet2014:383:630-67 doi:10.1016/S0140-6736(13)62407-1 pmid:24524782.

10 World Bank. World development indicators 2016. 2016. https://openknowledge.worldbank. org/bitstream/handle/10986/23969/9781464806834.pdf.

Published by the BMJ Publishing Group Limited. For permission to use (where not already granted under a licence) please go to http://group.bmj.com/group/rights-licensing/ permissions

This is an Open Access article distributed in accordance with the Creative Commons Attribution Non Commercial (CC BY-NC 4.0) license, which permits others to distribute, remix, adapt, build upon this work non-commercially, and license their derivative works on different terms, provided the original work is properly cited and the use is non-commercial. See: http://creativecommons.org/licenses/by-nc/4.0/. 


\section{Key messages:}

Achieving the sustainable development goals will require a new transformative governance for health which focuses on intersectionality and partnership

Think tanks and academic institutions have a crucial role to play in realising and accelerating action for sustainable development

Six core areas will contribute to the achievement of the SDGs-developing elements of governance, increasing political accountability for sustainable development, engaging national and global stakeholders, identifying new solutions to systemic challenges in intersectoral working, enabling joint learning, and knowledge sharing

We invite think tanks and academic institutions to join this effort in the form of a Global Health Policy Think Tank Network 